\title{
Corrigendum: Corticosterone Concentrations Reflect Parental Expenditure in Contrasting Mating Systems of Two Coucal Species
}

\author{
Wolfgang Goymann ${ }^{1,2 *}$, Monika Trappschuh ${ }^{1}$ and Felister Urasa ${ }^{3}$ \\ ${ }^{1}$ Abteilung für Verhaltensneurobiologie, Max-Planck-Institut für Ornithologie, Seewiesen, Germany, ${ }^{2}$ Coucal Project, Chimala, \\ Tanzania, ${ }^{3}$ Department of Zoology, University of Dar es Salaam, Dar es Salaam, Tanzania
}

Keywords: centropus, classical polyandry, glucocorticoids, mating system, parental care, sex-role reversal, social monogamy

\section{A corrigendum on}

Corticosterone Concentrations Reflect Parental Expenditure in Contrasting Mating Systems of Two Coucal Species

by Goymann, W., Trappschuh, M., and Urasa, F. (2017). Front. Ecol. Evol. 5:15. doi: $10.3389 /$ fevo.2017.00015

\section{OPEN ACCESS}

Edited and reviewed by:

Carlos Alonso Alvarez,

Consejo Superior de Investigaciones

Cientificas (CSIC), Spain

*Correspondence:

Wolfgang Goymann

goymann@orn.mpg.de

Specialty section:

This article was submitted to Behavioral and Evolutionary Ecology, a section of the journal

Frontiers in Ecology and Evolution

Received: 09 December 2017 Accepted: 22 December 2017 Published: 12 January 2018

Citation:

Goymann W, Trappschuh M and Urasa F (2018) Corrigendum: Corticosterone Concentrations Reflect Parental Expenditure in Contrasting Mating Systems of Two Coucal

Species. Front. Ecol. Evol. 5:176. doi: 10.3389/fevo.2017.00176
In the original article, there was an error. In the last paragraph of the Results section on page 7 we reported the results of baseline corticosterone concentrations in relation to the number of fledglings. In the statistical results we accidentally stated "feeding rate slope" when actually the slope of the number of fledglings was meant.

A correction has been made to the results section, page 7, last paragraph:

Baseline corticosterone concentrations of parenting male black coucals $(N=29)$, parenting female white-browed coucals $(N=19)$, and parenting male white-browed coucals $(N=14)$ were unrelated to the number of fledglings (male black coucals: number of fledglings $=-0.007$ [ -0.031 to 0.016$], \mathrm{P}(\beta)=0.26$; time between sampling and bleeding: slope $=0.16[-0.10$ to 0.43 ], $\mathrm{P}(\beta)=0.89$; marginal and conditional $R^{2}=0.02$; female white-browed coucals: number of fledglings $=0.02$ [ -0.05 to 0.08$], P(\beta)=0.68$; time between sampling and bleeding: slope $=0.06$ [ -0.27 to 0.39$], \mathrm{P}(\beta)=0.64$; marginal and conditional $R^{2}=0.01$; male white-browed coucals: number of fledglings $=0.01[-0.05$ to 0.08$], P(\beta)=0.65$; time between sampling and bleeding: slope $=-0.01\left[-0.38\right.$ to 0.36 ], $\mathrm{P}(\beta)=0.46$; marginal $R^{2}=0.004$ and conditional $R^{2}=0.05$ ).

The authors apologize for this semantic error and state that this does not change the scientific conclusions of the article in any way.

The original article has been updated.

Conflict of Interest Statement: The authors declare that the research was conducted in the absence of any commercial or financial relationships that could be construed as a potential conflict of interest.

Copyright $\odot 2018$ Goymann, Trappschuh and Urasa. This is an open-access article distributed under the terms of the Creative Commons Attribution License (CC BY). The use, distribution or reproduction in other forums is permitted, provided the original author(s) or licensor are credited and that the original publication in this journal is cited, in accordance with accepted academic practice. No use, distribution or reproduction is permitted which does not comply with these terms. 